\title{
Determination of Biuret Content in Fertilizers by High Performance Liquid Chromatography: Single-Laboratory Validation and Collaborative Ring Test Study
}

\author{
Deren $\mathrm{Chu}^{1,2}$, Michael M. Hojjatie ${ }^{3 *}$ and Gang Liu ${ }^{1,2 *}$ \\ ${ }^{1}$ Shanghai Research Institute of Chemical Industry, Testing Center, No. 345 Yunling Rd.(E), Shanghai, China \\ ${ }^{2}$ China National Center for Quality Supervision and Testing of Fertilizers (Shanghai), China \\ ${ }^{3}$ Tessenderlo Kerley, Inc., Research and Development Department, 2248 W. Lower Buckeye, Phoenix, Arizona, USA \\ ${ }^{*}$ Corresponding authors: Michael M. Hojjatie, Tessenderlo Kerley, Inc., Research and Development Department, 2248 W. Lower Buckeye, Phoenix, Arizona; E-mail: \\ mhojjatie@tkinet.com \\ Gang Liu, Shanghai Research Institute of Chemical Industry, Testing Center, No. 345 Yunling Rd.(E), Shanghai, China; E-mail: lgsds@vip.163.com
}

Received: August 15, 2019; Accepted: September 30, 2019; Published: October 10, 2019;

\begin{abstract}
Urea or urea-based fertilizers has become the leading form of nitrogen fertilizers around the world. Biuret, as one of major by-products formed during the manufacturing of urea, was proved to be harmful to plant growth. A Single-Laboratory Validation (SLV) study for a newly proposed High Performance Liquid Chromatography (HPLC) method was conducted. A total of six samples were tested in the SLV study: two urea samples, and four compound fertilizers with various compositions from different sources. In addition, one biuret standard from Aldrich ${ }^{\oplus}$ and one biuret reference from Alfa Aesar ${ }^{\circledR}$ were used as standard materials. The system was linear over a concentration range of $0 \sim 200$ ppm biuret, with a correlation coefficient $\geq 0.999$. Recoveries were determined by spiking three of the validation samples with known amounts of biuret standard solutions and measuring the biuret level according to the method. The recovery rates lies between $98.14 \%$ and $107.24 \%$. Method precision was determined by analyzing of six validation samples under five replicate analyses, the RSDs ranged from $0.69 \%$ to $1.85 \%$. Further study by Liquid Chromatography-Tandem Mass Spectrometry (LC-MS/MS) has revealed that the biuret was well-separated from urea and other $\mathrm{N}$-containing compounds in the system by this method. Moreover, the proposed method is verified in the international Collaborative Ring Test (CRT) study organized by ISO/TC 134 "Fertilizers and Soil Conditioners". Systematically statistical analysis on the data obtained has proven that this method is capable of effectively monitoring biuret content in a wide range of fertilizers.
\end{abstract}

Keywords: Biuret, Collaborative Ring Test, Fertilizer, High Performance Liquid Chromatography, International Standard, Single-Laboratory Validation

\section{Introduction}

Fertilizer has played an important role in improving both the quantity and quality of agricultural products [1-2]. Recently, urea, or urea-based fertilizers (Including urea formaldehyde slow release fertilizer, urea ammonium nitrate solution, sulfur coated urea, ureabased complex/compound fertilizer, etc.) has become the leading form of nitrogen fertilizers around the world, while some agricultural and environmental problems raised by the application of urea and ureabased fertilizers have attracted more and more attention [3-4]. Biuret, also known as 2-imidodicarbonic diamide $\left(\mathrm{NH}_{2} \mathrm{CONHCONH}{ }_{2}\right)$, is one of major by-products formed when molten urea was heated near or above its melting point during the manufacturing of urea and urea-based fertilizers [5-6]. The toxicity of biuret to plants was first observed and reported in the 1950s by US scientists during observing damages caused by urea foliage sprays on orchard plants such as citrus and pineapples [7-8]. The exact mechanism of biuret damage to different plants is still under investigation, but the harmful effects of high concentration of biuret to some sensitive plant species have been well documented $[4,7,8]$, and many regulations/standards concerning the maximum allowed concentrations and/or the analysis methods have been published around the world [9-14].

There are at least three analytical methods available for the determination of biuret in fertilizers, including the traditional spectrophotometric methods [10-13], the atomic absorption spectrophotometric methods [14] and the HPLC methods $[6,11,15]$. The first two methods are based on the formation of complexation of biuret with copper ions [Cu(II)], and subsequent determination of the $\mathrm{Cu}(\mathrm{II})$ compound concentration by spectrophotometry $[6,10,14]$. There are two significant disadvantages of spectrophotometric methods: first, the formation of chromatic copper complexation, although well-known as the "Biuret Reaction", is actually not the specific character of biuret, many other compounds such as ureacondensates (e.g. triuret), peptides and proteins may interfere with this complexation [15,19] second, both these spectrophotometric methods are complex and tedious, and are therefore more prone to multiple sources of error [6,11-14].

Recently, the HPLC methods have shown superiority over other types of methods, owing to their ability to quantitatively determine 
biuret content by completely separating biuret from numerous ureacondensates $[6,11,15]$. Some HPLC methods utilizing the C18 column with the detection wavelength of $200 \mathrm{~nm}$ [11] has been found to be effective for a variety of fertilizers, but could lose its efficacy when some specific compounds (e.g. nitrate, with strong adsorption under 200 $\mathrm{nm}$ ) are present in the fertilizers (e.g. Urea Ammonium Nitrate (UAN) solution, nitrate-containing complex/compound fertilizer, etc.). To seek a uniform, quick and accurate method for the determination of biuret content in fertilizers [16,17], a high performance liquid chromatography method for the determination of biuret content in fertilizers was developed. A Single-Laboratory Validation (SLV) and systematically statistical analysis on the data obtained had proven that the proposed method was capable of effectively monitoring biuret content in a wide range of fertilizers. The reproducibility of the method was verified in the international Collaborative Ring Test (CRT) study organized by ISO/TC 134 "Fertilizers and Soil Conditioners". On the basis of accuracy and precision of the results obtained in both SLV and CRT studies, it was conclude that the method is capable of measuring the amount of biuret present in the urea containing fertilizer accurately and with no interference from other urea or its adducts.

\section{Experimental Section}

This proposed method specifies the test procedure for the determination of the biuret content in liquid and solid urea containing fertilizers based on the HPLC method.

\section{A. Principle}

The biuret content in the fertilizer is extracted by aqueous acetonitrile mobile phase, and separated from other contents by reversed liquid chromatography on a propyl amino column, and the peak is detected by a UV detector attached to the HPLC. The external standard method is applied to determine the biuret content in fertilizer samples.

\section{B. Reagents \&Validation Materials}

\section{(a) Reagents}

All reagents were of analytical grade. Acetonitrile (HPLC grade, Merck Co. Ltd., Germany) was used for preparation of the mobile phase. Deionized distilled water $\left(18 \mathrm{MOhm}^{*} \mathrm{~cm}\right)$ was used throughout the experiment. Biuret standard material (>99\%, CAS 108-19-0, Lot $\#$ BCBH8859V) was purchased from Sigma-Aldrich ${ }^{\circledR}$ and was used for the HPLC quantitative analysis, and biuret reference material $(>97 \%$, CAS 108-19-0, Lot \#L00812) from Alfa Aesar ${ }^{\circledR}$ were used in the LCMS/MS qualitative analysis.

\section{(b) Validation Materials}

Two kinds of urea (SLV-054, SLV-108) and four kinds of compound fertilizers (SLV-003, SLV-125, SLV-012, SLV-114) from different sources were used as Single-Laboratory Validation (SLV) materials and are listed in Table 1. Each fertilizer sample to be tested has its distinguished content level of biuret. In order to establish a globally accepted analytical method, the validation materials for the Collaborative Ring Test (CRT) were selected to represent a wide variety of commercially available fertilizer products of different sources and manufacture processes. Seven different fertilizer products, including both liquid and solid urea-based fertilizers were selected for CRT and listed in Table 1, with biuret contents in the range of $0.10 \% \sim 1.01 \%$ (mass fraction).

Table 1. List of validation materials

\begin{tabular}{|c|c|c|c|}
\hline $\begin{array}{c}\text { Serial } \\
\text { number }\end{array}$ & Type of fertilizer & $\begin{array}{l}\text { Declared } \\
\text { grade }^{c}\end{array}$ & Note (raw material) \\
\hline SLV-054 ${ }^{\mathrm{a}}$ & urea & $46-0-0$ & / \\
\hline SLV-108 & urea & $46-0-0$ & / \\
\hline SLV-003 & compound fertilizer & $15-15-15$ & $\begin{array}{l}\text { urea, monoammonium } \\
\text { phosphate, ammonium } \\
\text { sulphate, potassium } \\
\text { chloride }\end{array}$ \\
\hline SLV-125 & compound fertilizer & $25-10-16$ & $\begin{array}{l}\text { urea, monoammonium } \\
\text { phosphate, potassium } \\
\text { chloride, ammonium } \\
\text { chloride }\end{array}$ \\
\hline SLV-012 & compound fertilizer & $15-15-15$ & $\begin{array}{l}\text { urea, monoammonium } \\
\text { phosphate, potassium } \\
\text { sulphate }\end{array}$ \\
\hline SLV-114 & compound fertilizer & $25-11-10$ & $\begin{array}{l}\text { urea, monoammonium } \\
\text { phosphate, calcium } \\
\text { superphosphate, potassium } \\
\text { sulphate }\end{array}$ \\
\hline CRT $-00^{1} \mathrm{~b}$ & $\begin{array}{l}\text { NPK compound } \\
\text { fertilizer }\end{array}$ & $\mathrm{N} / \mathrm{A}^{\mathrm{d}}$ & / \\
\hline CRT -002 & $\begin{array}{l}\text { urea formaldehyde } \\
\text { complex fertilizer }\end{array}$ & N/A & / \\
\hline CRT -003 & urea & N/A & / \\
\hline CRT -004 & $\begin{array}{l}\text { NPK complex } \\
\text { fertilizer }\end{array}$ & N/A & / \\
\hline CRT -005 & $\begin{array}{l}\text { urea ammonium } \\
\text { nitrate (UAN) } \\
\text { solution }\end{array}$ & N/A & urea, ammonium nitrate \\
\hline CRT -006 & $\begin{array}{l}\text { urea formaldehyde } \\
\text { slow release liquid } \\
\text { fertilizer }\left(\text { Trisert }^{\mathbb{R}} \text { ) }\right.\end{array}$ & N/A & $\begin{array}{l}\text { triazone, as well as other } \\
\text { urea-condensates }\end{array}$ \\
\hline CRT -007 & $\begin{array}{l}\text { polymer sulfur } \\
\text { coated urea (PSCU) }\end{array}$ & N/A & / \\
\hline
\end{tabular}

a $\mathrm{SLV}=$ single-laboratory validation

${ }^{\mathrm{b}} \mathrm{CRT}=$ collaborative ring test

${ }^{c}$ Declared grade listed in the order of $\mathrm{N}-\mathrm{P}_{2} \mathrm{O}_{5}-\mathrm{K}_{2} \mathrm{O}$

${ }^{\mathrm{d}} \mathrm{N} / \mathrm{A}=$ not available

All solid fertilizer samples were grinded until they passed through a sieve of aperture size $0.5 \mathrm{~mm}$, and mixed thoroughly for homogeneity before analysed. All liquid fertilizer samples mixed thoroughly for homogeneity before analyses.

\section{Apparatus and Analysis Conditions}

Ordinary laboratory apparatus, and

(a) High performance liquid chromatography (HPLC). - A Waters ${ }^{\circledR}$ 1525-2489-2707 HPLC system with a UV absorption detector 
having a minimum detection wavelength of $190 \mathrm{~nm}$. LC operation conditions were: LC column, $250 * 4.6 \mathrm{~mm}$ propylamine $\left(\mathrm{NH}_{2}\right)$ column with $5 \mu \mathrm{m}$ particle size (APS-2 Hypersil, ThermoFisher Co. Ltd. Part \#30705-254630 or Spherex $\mathrm{NH}_{2}$, Phenomenex Co. Ltd. Part \#00G-00051-E0); mobile phase, $85 \%$ (v/v) acetonitrile in water; elution mode, isocratic; flow rate, $1.0 \sim 1.3 \mathrm{ml} / \mathrm{min}$; injection volume, $10 \mu \mathrm{l}$; column temperature, $30 \sim 35{ }^{\circ} \mathrm{C}$; and detection wavelength, $195 \mathrm{~nm}$.

(b) Liquid Chromatography-Tandem Mass Spectrometry (LC-MS/ MS). - A Shimadzu 20ADXR HPLC system with a UV absorption detector was used for LC separation. An AB Sciex Triple TOF ${ }^{\circledR}$ 4600 with an ESI source in positive ion mode with Analyst ${ }^{\circledR}$ software was used to control the LC and the MS. LC operation conditions were set as the same as the Waters ${ }^{\circledR}$ HPLC system previously described, the MS operation conditions were: ion source, ESI; scan mode, MS(30D 450D)+ MS/MS(30D 450D); curtain gas pressure, $35 \mathrm{psi}$; ion spray voltage, $5500 \mathrm{~V}$; heater temperature, $600 \mathrm{oC}$; ion source gas 1 pressure, $50 \mathrm{psi}$; ion source auxiliary gas 2 pressure, 50psi; and collision gas, medium.

(c) Ultrasonic bath. - purchased from Shanghai Kudos ultrasonic instrument Co.,Ltd.

(d) Sample sieve. - With the aperture size of $0.50 \mathrm{~mm}$.

(e) Syringe-driven filter. - With organic filter membrane of $0.22 \mu \mathrm{m}$ pores.

\section{Procedures}

\section{(a) Preparation of Test Solution:}

For the solid fertilizer samples, weigh $0.1 \mathrm{~g} \sim 0.5 \mathrm{~g}$ test sample (accurately to $0.0002 \mathrm{~g}$, with biuret content of $1 \mathrm{mg} 2 \mathrm{mg}$ ca.) into a $25 \mathrm{ml}$ beaker. Add $10 \mathrm{ml}$ mobile phase and dissolve using an ultrasonic bath for $10 \mathrm{~min}$. Transfer to a $25 \mathrm{ml}$ volumetric flask and dilute to volume with mobile phase. Mix thoroughly and leave standing, filter with a syringe filer to obtain the test solution. For the liquid fertilizer samples, directly transfer $0.1 \mathrm{ml} \sim 0.5 \mathrm{ml}$ of the test sample (accurately to $0.001 \mathrm{ml}$, with biuret content of $1 \mathrm{mg} \mathrm{2} \mathrm{mg} \mathrm{ca}$.) into a $25 \mathrm{ml}$ volumetric flask, dilute to volume with mobile phase. Mix thoroughly and leave standing, filter with syringe filer to obtain the test solution.

\section{(b) Preparation of Biuret Stock Solution and Working Standard} Solutions:

Weigh $0.5000 \mathrm{~g}$ biuret standard material [B(a)], dissolve by mobile phase, and transfer into a $1000 \mathrm{ml}$ volumetric flask, dilute to volume with mobile phase and mix to form the biuret stock solution. For the biuret working standard solution, pipette $0.00 \mathrm{ml}, 0.50 \mathrm{ml}, 1.00 \mathrm{ml}$, $3.00 \mathrm{ml}, 5.00 \mathrm{ml}$ and $10.00 \mathrm{ml}$ biuret stock solution into 6 separate 25 $\mathrm{ml}$ volumetric flasks. Dilute with respective volumes of mobile phase and make up to the mark and mix thoroughly. Filter with $0.22 \mu \mathrm{m}$ organic filter membrane (Table 2).

\section{(c) Determination of the Biuret Content and Calculation}

Ensure the HPLC apparatus operating conditions are optimized. Successively inject $10 \mu \mathrm{l}$ working standard solution and determine the series of standard solution. Draw the standard curve and deduce the linear regression equation by the average peak areas of the biuret and the corresponding mass. Determine the test solution by the same procedure, measure the peak area, and calculate the biuret mass in each test solution according to the standard curve or linear regression equation.

Table 2. Preparation of biuret working standard solutions

\begin{tabular}{|c|c|c|}
\hline $\begin{array}{c}\text { Volume of biuret } \\
\text { standard solution (ml) }\end{array}$ & Mass of biuret (mg) & $\begin{array}{c}\text { Concentration of } \\
\text { biuret (mg/kg) }\end{array}$ \\
\hline 0.50 & 0.25 & 10.0 \\
\hline 1.00 & 0.50 & 20.0 \\
\hline 3.00 & 1.50 & 60.0 \\
\hline 5.00 & 2.50 & 100.0 \\
\hline 10.00 & 5.00 & 200.0 \\
\hline
\end{tabular}

The mass fraction of biuret (\%), w, is calculated as follows:

$$
\mathrm{w}=\frac{\mathrm{m}_{1} \times 10^{-3}}{\mathrm{~m}} \times 100
$$

Where $\mathrm{m}_{1}$ is the mass of biuret in $\mathrm{mg}$, of the test solution, calculated according to the standard curve or linear regression equation corresponding to the peak areas; $\mathrm{m}$ is the mass in $\mathrm{g}$, of the test portion. The mass fraction of biuret is the arithmetic average of two parallel test results. The statistical analysis of the data obtained from the SLV and CRT study was performed mainly according to procedures in ISO 5725-2:1994 [18].

\section{Results and Discussion}

\section{A. Lc Chromatogram and Calibration Curve}

The LC chromatogram of biuret standard material is shown in Figure 1. The observed peak is attributed to the biuret, and no any other significant contamination could be found, showing high purity of the biuret standard material $[\mathrm{B}(\mathrm{a})]$. The calibration plot illustrated that the method was linear over the region of 10.00 to $200.0 \mathrm{mg} / \mathrm{kg}$, with a correlation coefficient $\geq 0.999$.

\section{B. Lc-Ms/Ms Analysis}

LC-MS/MS was introduced to analyze biuret reference material (> 97\% from Alfa Aesar ${ }^{\circledR}$ ) and some representative fertilizer samples, in order to verify the separation of biuret from many other compounds within various fertilizer matrices by the proposed method. Figure 2(a) depicted the LC-MS/MS quantitation ion chromatogram of biuret reference material; Figure 2(b) shows the chromatogram of sample \#SLV-054 (Urea); Figure 2(c) is the chromatogram of sample \#SLV114 (Compound Fertilizer); and Figure 2(d) shows the proposed target compounds and their fragmentation pattern under positive ion ESI mode, corresponding to all the significant peaks found in quantitation ion chromatograms. Compound $\mathrm{C} 1$ with the retention time of 3.03 3.04 min corresponding to the protonated molecular ions $[\mathrm{M}+\mathrm{H}]^{+}$at $\mathrm{m} / \mathrm{z} 147.0$ was identified as triuret $\left(\mathrm{C}_{3} \mathrm{H}_{7} \mathrm{~N}_{4} \mathrm{O}_{3}{ }^{+}\right)$, which was also served as the precursor ion for fragments with $[\mathrm{M}+\mathrm{H}]^{+}$at $\mathrm{m} / \mathrm{z} 130\left(\mathrm{C}_{3} \mathrm{H}_{7} \mathrm{~N}_{3} \mathrm{O}_{3}^{+}\right), 104\left(\mathrm{C}_{2} \mathrm{H}_{6} \mathrm{~N}_{3} \mathrm{O}_{2}^{+}\right), 87\left(\mathrm{C}_{2} \mathrm{H}_{3} \mathrm{~N}_{2} \mathrm{O}_{2}^{+}\right)$ 
and $61\left(\mathrm{CH}_{5} \mathrm{~N}_{2} \mathrm{O}^{+}\right)$in the tandem MS/MS. Compound $\mathrm{C} 2$ with the retention time of 3.16 3.18 min corresponding to the protonated molecular ions $[\mathrm{M}+\mathrm{H}]^{+}$at $\mathrm{m} / \mathrm{z} 104.0$ could be identified as the target biuret $\left(\mathrm{C}_{2} \mathrm{H}_{6} \mathrm{~N}_{3} \mathrm{O}_{2}^{+}\right)$, which was also served as the precursor ion for fragments with $[\mathrm{M}+\mathrm{H}]^{+}$at $\mathrm{m} / \mathrm{z} 87\left(\mathrm{C}_{2} \mathrm{H}_{3} \mathrm{~N}_{2} \mathrm{O}_{2}^{+}\right)$and $61\left(\mathrm{CH}_{5} \mathrm{~N}_{2} \mathrm{O}^{+}\right)$ in the tandem MS/MS. Compound $\mathrm{C} 3$ with the retention time of 3.64 3.65 $\mathrm{min}$ corresponding to the protonated molecular ions $[\mathrm{M}+\mathrm{H}]^{+}$at $\mathrm{m} / \mathrm{z} 61$ could be identified as urea, which has the strongest ion peak in chromatogram 2(a) in which the urea was the dominant component. Particularly since urea's lone transition is the rather nonspecific loss of ammonia $\left(\mathrm{NH}_{3}\right)$ and due to its low molecular weight, urea formed no structurally significant ion by LC-MS/MS during our analysis. Compound $\mathrm{C} 4$ with the retention time of $4.62 \sim 4.63 \mathrm{~min}$ corresponding to the protonated molecular ions $[\mathrm{M}+\mathrm{H}]^{+}$at $\mathrm{m} / \mathrm{z} 133.0$ was identified as $\mathrm{N}, \mathrm{N}^{\prime}$-methylenediurea $\left(\mathrm{C}_{3} \mathrm{H}_{9} \mathrm{~N}_{4} \mathrm{O}_{2}^{+}\right)$, which was also served as the precursor ion for fragments with $[\mathrm{M}+\mathrm{H}]^{+}$at $\mathrm{m} / \mathrm{z} 73$ $\left(\mathrm{C}_{2} \mathrm{H}_{5} \mathrm{~N}_{2} \mathrm{O}^{+}\right)$and $61\left(\mathrm{CH}_{5} \mathrm{~N}_{2} \mathrm{O}^{+}\right)$in the tandem MS/MS.

\section{Calibration Plot}

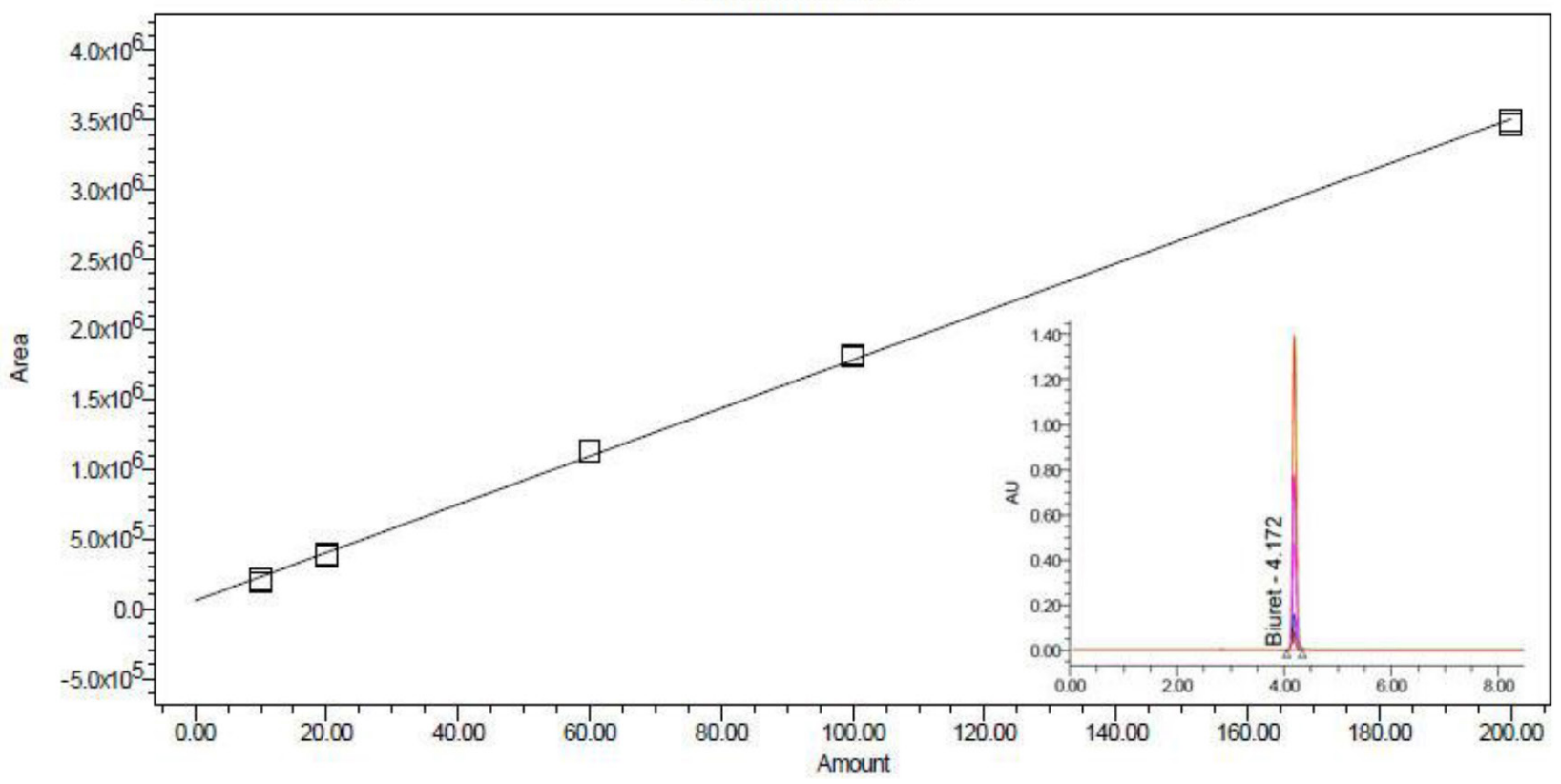

Figure 1. LC chromatogram of biuret standard and calibration curve

The LC-MS/MS result has shown that the propylamine $\left(\mathrm{NH}_{2}\right)$ column utilized in our proposed method can successfully separate biuret form its analogues such as urea, triuret and $\mathrm{N}, \mathrm{N}$ 'methylenediurea, thus indicated its possibility to be further extend to determine those aforementioned contaminants individually or simultaneously in a separate study.

\section{Accuracy and Method Applicability}

The accuracy of the proposed method was validated by the recovery rate test running for one urea and two kinds of compound fertilizers. In a typical procedure, a certain amount of biuret working standard solution with the concentrations of $60 \mathrm{mg} / \mathrm{kg}, 80 \mathrm{mg} / \mathrm{kg}$ and $100 \mathrm{mg} / \mathrm{kg}$ were spiked into the fertilizer sample, and then the test solutions were prepared and determined as described in the experimental section. The recovery rate was defined as the quotient of the recovery amount of the biuret divided by the amount of the biuret added. A summary of results tabulated in Table 3 below has shown that the spiked recoveries ranged from $98.14 \%$ to $107.24 \%$, with a mean recovery of $102.24 \%$.The recovery results met the requirement for standard method performances, in which the acceptable recovery limits for sample concentration around 100ppm $(\mathrm{mg} / \mathrm{kg})$ was given by $85 \% \sim 110 \%[20]$.
Method applicability has to be verified at a very early stage of method development, since many compounds existing in the fertilizer matrix would have peaks on the HPLC chromatogram and thus may interfere with the analysis of biuret. One sort of those compounds with great high concerning is nitrates, which usually are very common fertilizer components, with strong adsorption under $200 \mathrm{~nm}$. C18 columns were proven to be not suitable to analyze those fertilizer containing nitrates, simply because they cannot separate nitrates from the target compound biuret. In order to verify the proposed method's applicability, an extra portion of $0.1 \mathrm{~g}$ ammonium nitrate was added in validation sample SLV-114 during the recovery rate test, with the detection wavelength at $195 \mathrm{~nm}$.

Figure 3(a) depicts the HPLC chromatogram for validation sample SLV-114, and Figure 3(b) shows the HPLC chromatogram for validation sample SLV-114, spiked with $0.1 \mathrm{~g}$ ammonium nitrate. The peaks with retention time of $4.1 \mathrm{~min} c a$. in both chromatograms were identified as biuret; and the huge bump with retention time of 7.5 14 min $c a$. was attributed to the nitrate, and show a complete separation from the biuret and many other possible analogous compounds with potential interests. 

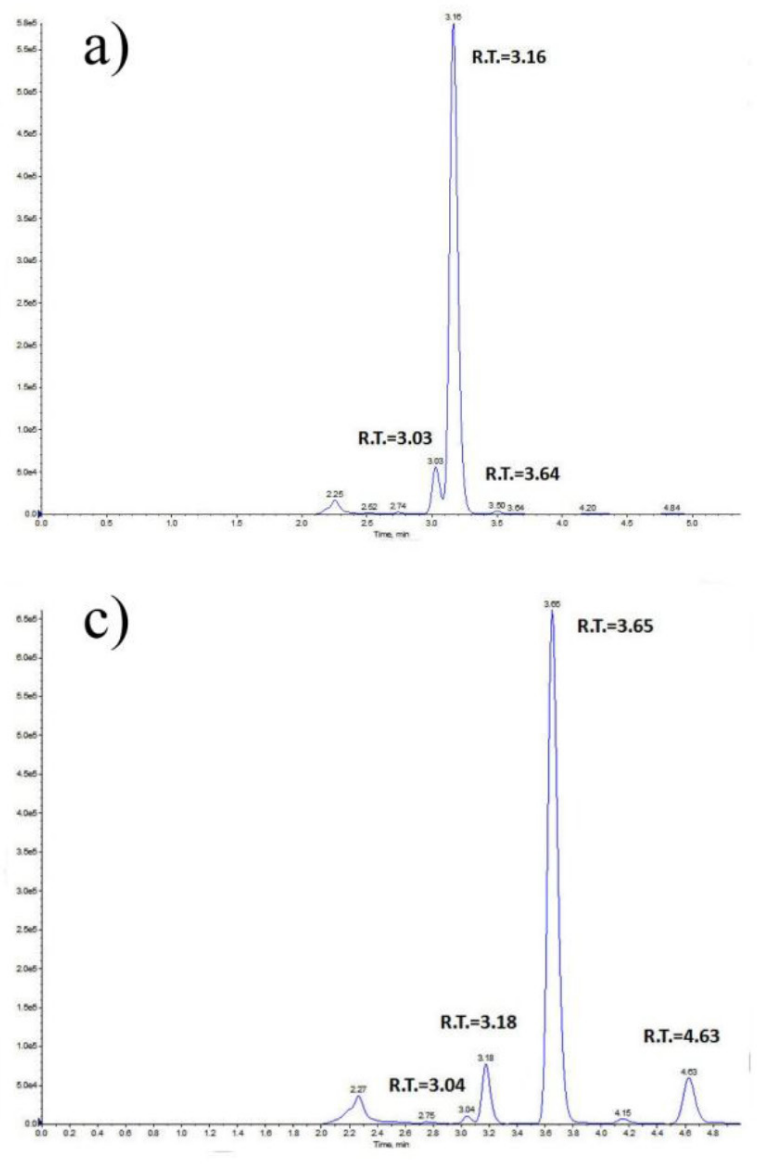

Figure 2. LC-MS/MS quantitation ion chromatograms for potential compounds in biuret reference material and fertilizer samples
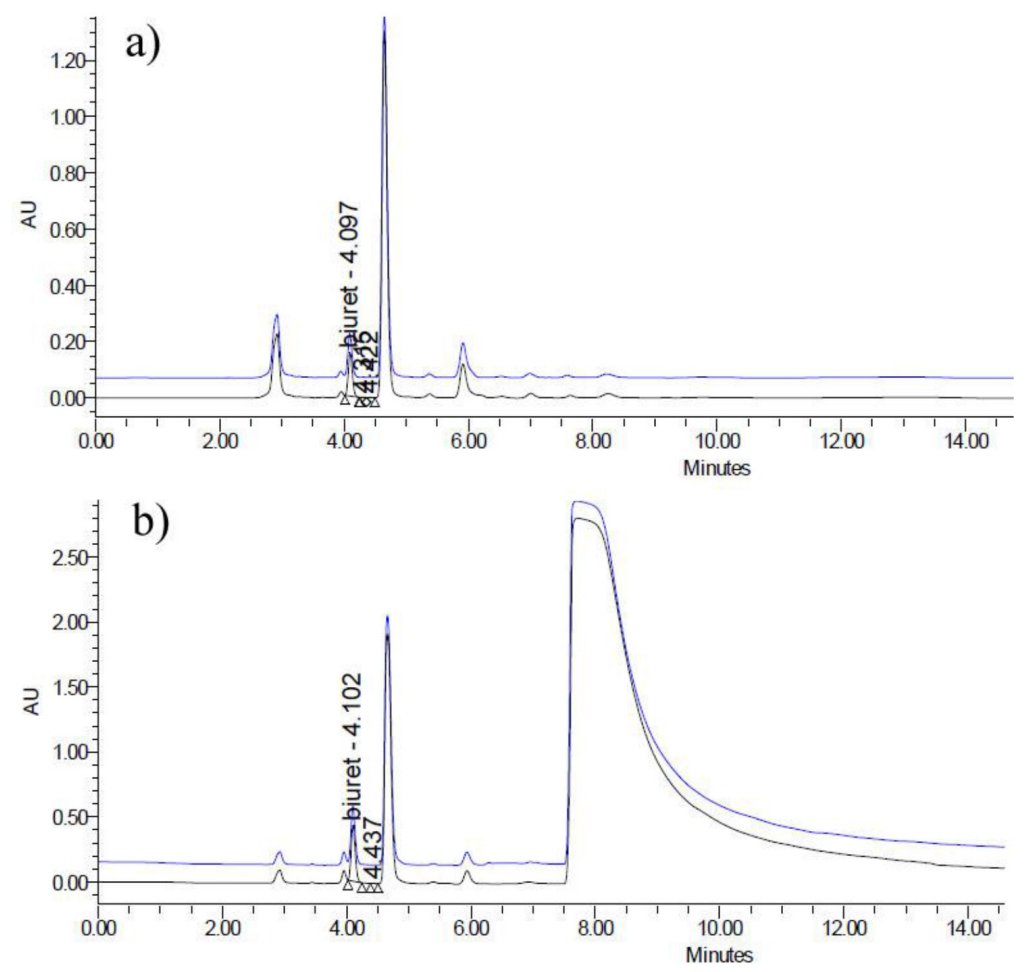

Figure 3. a) HPLC chromatogram for validation sample SLV-114; b) HPLC chromatogram for validation sample SLV-114, spiked with $0.1 \mathrm{~g}$ ammonium nitrate. 
Table 3. Recoveries for validation samples spiked with biuret

\begin{tabular}{|l|c|c|c|}
\hline $\begin{array}{c}\text { Serial } \\
\text { number }\end{array}$ & Type of fertilizer & $\begin{array}{c}\text { Spiking concentration } \\
(\mathbf{m g} / \mathbf{k g})\end{array}$ & Recovery (\%) \\
\hline SLV-108 & urea & 60 & 98.14 \\
\hline SLV-108 & urea & 80 & 101.71 \\
\hline SLV-108 & urea & 100 & 103.50 \\
\hline SLV-125 & compound fertilizer & 60 & 101.46 \\
\hline SLV-125 & compound fertilizer & 80 & 100.22 \\
\hline SLV-125 & compound fertilizer & 100 & 103.51 \\
\hline SLV-114 & compound fertilizer & 60 & 107.24 \\
\hline SLV-114 & compound fertilizer & 80 & 104.86 \\
\hline SLV-114 & compound fertilizer & 100 & 99.54 \\
\hline
\end{tabular}

a. Average recovery $=102.24 \%$.

b. In order to verify the method applicability, especially no interference from nitrate (common fertilizer component, with strong adsorption under $200 \mathrm{~nm}$ ), an extra portion of $0.1 \mathrm{~g}$ ammonium nitrate was added in validation sample SLV-114 during the recovery rate test.

\section{Precision}

In order to verify the precision of the proposed method, namely, to illustrate the repeatability of the test results, 5 parallel tests on all the six Single-Laboratory Validation (SLV) materials were performed respectively. The Relative Standard Deviations (RSD\%) were used to evaluate the results (Table 4) as follows:

Table 4. Precisions for validation samples

\begin{tabular}{|l|c|c|c|c|}
\hline $\begin{array}{c}\text { Serial } \\
\text { number }\end{array}$ & $\begin{array}{c}\text { Type of } \\
\text { fertilizer }\end{array}$ & $\begin{array}{c}\text { Results of 5 } \\
\text { parallel tests (\%) }\end{array}$ & $\begin{array}{c}\text { Average } \\
\text { test result } \\
\text { of biuret } \\
\mathbf{( \% )}\end{array}$ & $\begin{array}{c}\text { Relative } \\
\text { standard } \\
\text { deviations } \\
\text { (RSD, \%) }\end{array}$ \\
\hline SLV-054 & urea & $\begin{array}{c}1.019 ; 1.063 ; 1.065 ; \\
1.062 ; 1.060\end{array}$ & 1.054 & 1.85 \\
\hline SLV-108 & urea & $\begin{array}{c}0.621 ; 0.611 ; 0.610 ; \\
0.617 ; 0.612\end{array}$ & 0.614 & 0.76 \\
\hline SLV-003 & $\begin{array}{c}\text { compound } \\
\text { fertilizer }\end{array}$ & $\begin{array}{c}0.085 ; 0.086 ; 0.087 ; \\
0.087 ; 0.085\end{array}$ & 0.086 & 1.10 \\
\hline SLV-125 & $\begin{array}{c}\text { compound } \\
\text { fertilizer }\end{array}$ & $\begin{array}{c}0.949 ; 0.955 ; 0.967 ; \\
0.955 ; 0.950\end{array}$ & 0.955 & 0.75 \\
\hline SLV-012 & compound & $0.540 ; 0.533 ; 0.530 ;$ \\
fertilizer & $0.536 ; 0.535$ & 0.535 & 0.69 \\
\hline SLV-114 & compound & $0.334 ; 0.334 ; 0.333 ;$ \\
fertilizer & $0.332 ; 0.320$ & 0.331 & 1.81 \\
\hline
\end{tabular}

According to the results from Table 4, all the RSDs of 5 parallel tests lie within the range of $0.69 \% \sim 1.85 \%$. The method precision results met the requirement for standard method performances, in which the acceptable RSD limits for sample concentration around $1 \%$ was given by $2 \% c a$., thus implies that precision of the as-established method is quite convincible [20].

\section{E. Collaborative Ring Test Results}

As confirmed by the SLV test, the newly proposed HPLC method with propylamine column has shown a good separation of biuert from urea and other $\mathrm{N}$-containing compounds in many urea-containing fertilizer matrices. The proposed method also has a relatively wide dynamic linear range, convincing accuracy as well as precision. A similar method with minor variation on the chromatographic column for the determination of biuret in water-soluble, urea based commercial inorganic fertilizer materials, urea solutions and surfur-coated urea by another SLV test has been reported [6]. Also, an acetonitrile-free HPLC method with C18 column as the alternative method does exist [23]. A collaborative round robin test was first conducted to compare these three methods. Through careful studies of the data obtained in the collaborative round robin test, the two methods using acetonitrilewater (85:15 ratio) mobile phase are capable of separating the biuret in all the urea-containing fertilizers samples under this study, but the method using C18 column with water as a mobile phase showed some limitations based on the types of fertilizer $[17,23]$. Then, the proposed method with propylamine column is verified in an international Collaborative Ring Test (CRT) study organized by ISO/TC 134 "Fertilizers and Soil Conditioners".

Seven samples, together with the SOP files were sent to 13 globally participating laboratories to ensure that all the participants could meet the identical method requirements and uniformity. The samples choices have shown a very diverse spectrum, from solid fertilizers to liquid fertilizers, from single fertilizer matrix to compound/ complex fertilizers and from uncoated fertilizers to coated fertilizer, which including one NPK compound fertilizer (CRT-001), one urea formaldehyde complex fertilizer (CRT-002), one urea (CRT-003), one NPK complex fertilizer (CRT-004), one Urea Ammonium Nitrate (UAN) solution (CRT-005), one urea formaldehyde slow release liquid fertilizer (Trisert ${ }^{\circledR}$ ) (CRT-006) and one Polymer Sulfur Coated Urea (PSCU) (CRT-007).

Statistical analysis of these results was carried out in accordance with procedures in related ISO standards on statistics [18], and also referred to the AOAC Guidelines for Standard Method Performance Requirements [20]. Basically, The Cochran's tests and Grubbs' tests $[18,21-22]$ were initially performed on the data collected to eliminate outliers. The mean level $(\mathrm{m})$, the repeatability standard deviation $\left(\mathrm{s}_{\mathrm{r}}\right)$, the reproducibility standard deviation $\left(\mathrm{s}_{\mathrm{R}}\right)$ of this joint-proposed method were calculated and shown in Table 5 below.

An examination of the data in Table 5 above indicate that both the repeatability standard deviation $\left(\mathrm{s}_{\mathrm{r}}\right)$ and the reproducibility standard deviation $\left(\mathrm{s}_{\mathrm{R}}\right)$ tend to be irrelevant with the mean level of biuret $(\mathrm{mg} /$ $\mathrm{kg}$ ). Thus, according to the ISO standards 5725 on statistics, the precision of the proposed method can be represented by the average values of $s_{r}$ and $s_{R}$ over different mean levels, and should be quoted, as a percentage by mass, as:

Repeatability standard deviation, $\mathrm{s}_{\mathrm{r}}=7.71 \mathrm{E}-3$
Reproducibility standard deviation, $\mathrm{s}_{\mathrm{R}}=3.66 \mathrm{E}-2$

During the Collaborative Ring Test (CRT) studies, the method applicability and precision were further confirmed; moreover, some valuable comments from participating laboratories were received when the final results were submitted. Laboratory X reported that due to the delay of logistics they had used another amine column (GRACE Altima amino) instead, which led to a small variation on the retention 
time of biuret, but still attained a good separation. The committee still took their data into consideration since laboratory X's data had passed through the entire statistical test. This led to a note that "Other HPLC conditions that can achieve the same separation effects may be used." Laboratory Y reported that they have done a systematically research on the CRT-007 sample of Polymer Sulfur Coated Urea (PSCU) and had found that the biuret content determined has some relationship with the pre-treatment procedure of the sample, especially with the time of ultrasonic treatment during the dissolve process. The deduction was that the biuret content determined may vary due to the change of extraction percentage which linked to the pre-treatment procedure, and a detailed sample preparation procedure with respect to the time of ultrasonic treatment as precise as 10 minutes in the SOP as well as the draft international standard [17] is necessary. Overall, all the comments from the participating laboratories comments have helped to the further improvement of the proposed method.

Table 5. Mean level $(\mathrm{m})$, repeatability standard deviation $\left(\mathrm{s}_{\mathrm{r}}\right)$, and reproducibility standard deviation $\left(\mathrm{s}_{\mathrm{R}}\right)$ of the joint-proposed method.

\begin{tabular}{|c|c|c|c|c|c|c|c|}
\hline Sample & CRT-001 & CRT-002 & CRT-003 & CRT-004 & CRT-005 & CRT-006 & CRT-007 \\
\hline Number of valid data/outliers & $13 / 0$ & $13 / 0$ & $12 / 1$ & $13 / 0$ & $12 / 1$ & $13 / 0$ & $12 / 1$ \\
\hline Mean level of biuret, $\mathrm{m} \%(\mathrm{mg} / \mathrm{kg})$ & 0.62 & 0.53 & 1.01 & 0.31 & 0.24 & 0.94 & 0.10 \\
\hline Repeatability standard deviation $\left(\mathrm{s}_{\mathrm{r}}\right)$ & $1.03 \mathrm{E}-2$ & $7.81 \mathrm{E}-3$ & $8.84 \mathrm{E}-3$ & $4.57 \mathrm{E}-3$ & $3.14 \mathrm{E}-3$ & $1.79 \mathrm{E}-2$ & $1.43 \mathrm{E}-3$ \\
\hline Reproducibility standard deviation $\left(\mathrm{s}_{\mathrm{R}}\right)$ & $2.03 \mathrm{E}-2$ & $3.53 \mathrm{E}-2$ & $5.22 \mathrm{E}-2$ & $2.29 \mathrm{E}-2$ & $2.79 \mathrm{E}-2$ & $6.18 \mathrm{E}-2$ & $3.57 \mathrm{E}-2$ \\
\hline
\end{tabular}

\section{Conclusion}

A high performance liquid chromatography method for the determination of biuret content in fertilizers was developed for the ISO international standard 18643. A Single-Laboratory Validation (SLV) and systematically statistical analysis on the data obtained had proven that the proposed method was capable of effectively monitoring biuret content in a wide range of fertilizers. The reproducibility of the method was verified in the international Collaborative Ring Test (CRT) study organized by ISO/TC 134 "Fertilizers and Soil Conditioners". On the basis of accuracy and precision of the results obtained in both SLV and CRT studies, it was conclude that the method is capable of measuring the amount of biuret present in the urea containing fertilizer accurately and with no interference from other urea or its adducts.

\section{Acknowledgement}

This work was supported by Research Project for Technology Standard (11DZ0502600, 13DZ0502600, Funded by Science and Technology Commission of Shanghai Municipality, China P. R.). We are indebted to President Mr. William L. Hall Jr. and Secretary Mrs. Mojdeh R. Tabari from ISO/TC134 for many kind help. We would thank Dr. Ruud van Belzen from Yara Sluidkil B. V. to share with their alternative acetonitrile-free HPLC method for a three-side (CHN-USA-NED) round robin test as a preliminary research and Dr. Chengyuan Cai from AB Sciex-China Pte. Ltd. for help on LC-MS/ MS analysis.

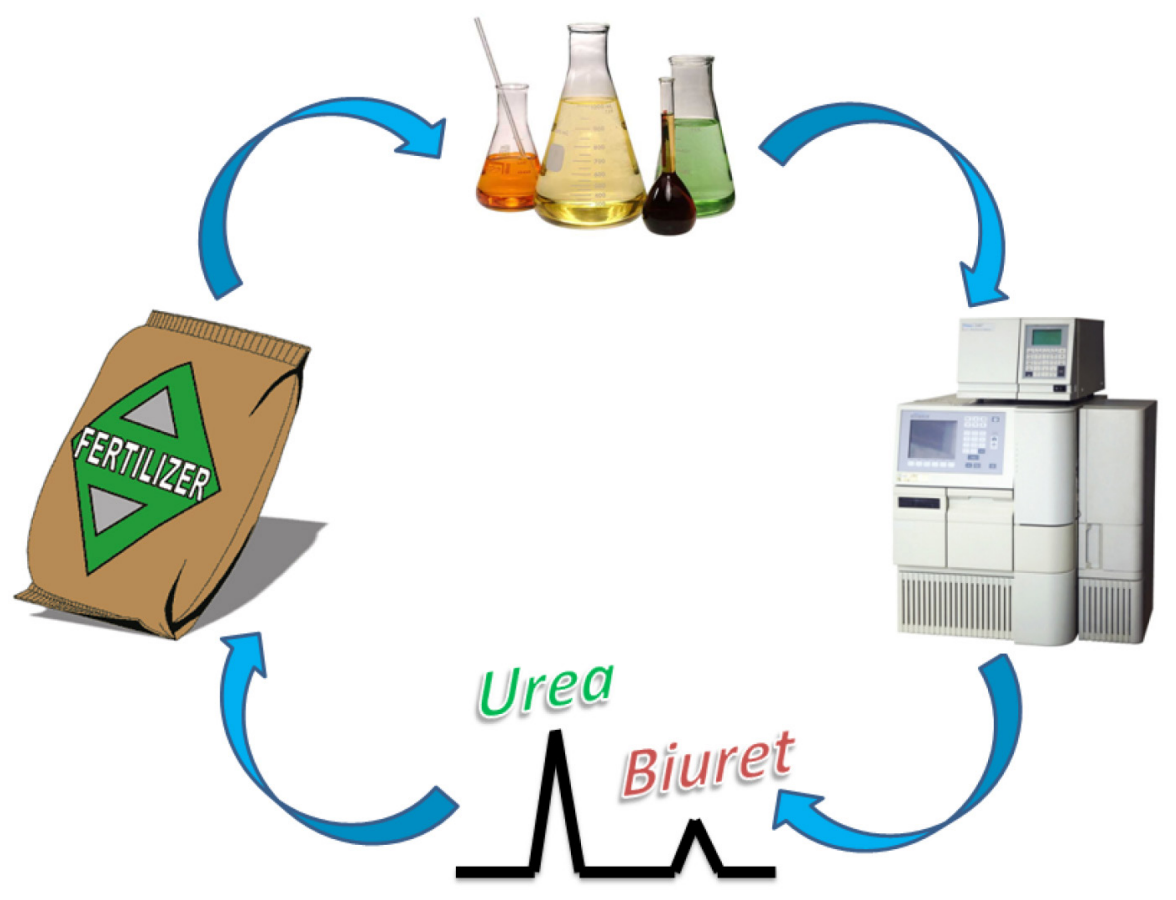


Michael M. Hojjatie (2019) Determination of Biuret Content in Fertilizers by High Performance Liquid Chromatography: Single-Laboratory Validation and Collaborative Ring Test Study

\section{References}

1. Morari F, VellidisG, Gay P (2011) Environment and human health effects: Fertilizers. In: J Nriagu (Ed), editor. Encyclopaedia of Environmental Health. Elsevier Science Publishers Pg No: 727-737.

2. Foley JA, Ramankutty N, Brauman KA, Cassidy ES, Gerber JS, et al. (2011) D.P.M. Nature 478: 337-342.

3. Hasan MM (1957) Biuret Phytotoxity. UCLA-Horticultural Science Publication, Los Angeles, $C A$.

4. Mikkelsen R L (2007) Better Crops 91: 6-7.

5. Redemann CE, Riesenfeld FC, Viola FS (1958) Ind. Eng. Chem 50: 633-636.

6. Hojjatie MM, Abrams D (2014) J. AOAC Int 97: 712-720.

7. Jones WW, (1954) Science 24: 499-500.

8. Sanford WG, Gowing DP, Young HY, Leeper RW (1954) Science 27: 349-350.

9. Slater JV (Ed) (2014) AAPFCO Official Publication No. 67, Laws and Regulations.

10. Fertilizers - Spectrophotometric determination of biuret in urea. EN 15479:2009.

11. Determination of biuret content for compound fertilizers (complex fertilizers). GB 22924-2008.

12. Determination of urea-Part 2: Biuret content -Spectrophotometric method. GB 2441.2-2010.

13. AOAC Official Method 960.04. Biuret in fertilizers-Spectrophotometric method.

14. AOAC Official Method 976.01. Biuret in fertilizers-Atomic absorption spectrophotometric method.

15. Thomas PM, Ernest RA, Robert GH, Robert CH (1982) Anal. Chem 54: 1504-1507.

16. ISO/TC 134 Business Plan (2012) Pg No: 1-2.

17. Fertilizers and soil conditioners - Determination of biuret content of urea-based fertilizers - HPLC method. ISO DIS 18643.

18. Accuracy (trueness and precision) of measurement methods and results-Parts 2: Basic method for the determination of repeatability and reproducibility of a standard measurement method. ISO 5725-2:1994.

19. Strulei CA, Averell PR (1970) The Analytical Chemistry of Nitrogen and Its Compounds. Wley-Interscience New York, Part 2, Chapter 11.

20. Official Methods of Analysis of AOAC International, $19^{\text {th }}$ Edition (2012) Appendix F: Guidelines for Standard Method Performance Requirements.

21. Grubbs FE (1969) Technometrics 11: 1-21.

22. Grubbs FE, Beck G (1972) Technometrics 14: 847-854.

23. R. van Belzen et al. (2014) Unpublished results on the HPLC method for determination of biuret in fertilizers.

\section{Citation:}

Chu D, Hojjatie MM, Liu G (2019) Determination of Biuret Content in Fertilizers by High Performance Liquid Chromatography: Single-Laboratory Validation and Collaborative Ring Test Study. J Pharmacol Pharm Res Volume 2 (3): 1-8. 